\title{
Contaminación por bioaerosoles en el relleno sanitario del Gobierno Autónomo Descentralizado Municipal de Riobamba.
}

\section{Contamination by bioaerosols in the sanitary landfill of the government decentralized autonomous municipal de Riobamba.}

Manolo Alexander Córdova Suárez. ${ }^{1}$, José Geovanny Vega Pérez. ${ }^{2}$, Oscar Eduardo Ruíz Robalino. ${ }^{3}$, Bélgica Susana Campaña Robayo. ${ }^{4} \&$ Gabriél Josué Navarrete Marcial. ${ }^{5}$

Recibido: 18-09-2017 / Revisado: 12-11-2017 Aceptado: 25-12-2018/ Publicado: 01-01-2018

Abstract.

DOI: https://doi.org/10.33262/cienciadigital.v2i3.168

The air pollution generated by the Urban Solid Waste (RSU) deposited in the Sanitary Landfills of the Decentralized Autonomous Governments (GADS) constitute a global environmental concern (Jiménez, 2012); the use of landfills as a waste disposal method is highly replicated. However, due to the compilation of foods and allowed cells (Pagalilauan et al., 2018) that are transported in the air. Exposure to these bioaerosols is associated with a wide range of infectious, toxic, acute, allergic and even cancer diseases (Douwes et al., 2003). Due to the daily accumulation of MSW and its nature, the Porrón Landfill of the city of Ríobamba results in a high level of biological risk for workers and inhabitants of the sector.

\footnotetext{
1 G+ Energy-Risks \& Engineering Group, Department of Food Science and Engineering, Technical University of Ambato, Ambato-Ecuador, ma.cordova@uta.edu.ec

2 G+ Energy-Risks \& Engineering Group, Department of Food Science and Engineering, Technical University of Ambato, Ambato-Ecuador,jg.vega@uta.edu.ec

3 G+ Energy-Risks \& Engineering Group, Department of Food Science and Engineering, Technical University of Ambato, Ambato-Ecuador, oe.ruiz@uta.edu.ec

${ }^{4}$ G+ Energy-Risks \& Engineering Group, Department of Food Science and Engineering, Technical University of Ambato, Ambato-Ecuador, belgisu@ hotmail.es

5 G+ Energy-Risks \& Engineering Group, Department of Food Science and Engineering, Technical University of Ambato, Ambato-Ecuador, josue_joseph99@hotmail.com
} 
Methods: The sampling of air was done during four weeks from Monday to Friday divided into two parts: the first in the area of hospital waste and the second in the area of common waste. The air was aspirated with syringes of $20 \mathrm{~cm} 3$ and was deposited in the Brain-Heart Infusion culture broth, with 50 aspirations for each of the samples. These samples were incubated at $37^{\circ} \mathrm{C}$ for 48 hours to obtain optimal growth of the bacteria and then planted in two different culture media, being Triphena Soya Agar and MacConkey Agar. Finally, the bacterial species identified were associated with the risk groups mentioned by Royal Decree 664/1997

Results: We identified 103 morphologically different colonies from which we observed 12 different genera of bacteria isolated from the culture media: Shigella, Enterococcus, Enterobacter, Pantoea, Hafnia, Salmonella, Citrobacter, Staphylococcus, Escherichia, Klebsiella, Proteus and Providence, of the 14 species $57 \%$ represent at the level of biological risk of group 2, 29\% correspond to group 3 and $14 \%$ are unidentified species.

Conclusion: Concentrations of colony forming units were determined between $1.95 \times 10+8 \mathrm{CFU} / \mathrm{ml}$ and $2.78 \times 10+9 \mathrm{CFU} / \mathrm{ml}$ with the presence of dangerous bacteria belonging to level 2 and 3 in terms of biological risk and which gave higher concentration at a temperature of $16^{\circ} \mathrm{C}$, relative humidity of $60 \%$, organic matter of $55 \%$ present in the filling.

Keywords: Sanitary landfill, pathogenic bacteria, Environmental contamination.

\section{Resumen.}

La contaminación del aire generado por los Residuos Sólidos Urbanos (RSU) depositados en los Rellenos Sanitarios de los Gobiernos Autónomos Desentralizados (GADS) constituyen una preocupación ambiental de carácter mundial (Jimenez, 2012); el uso de Rellenos Sanitarios como un método de eliminación de desechos es muy replicado. Sin embargo, debido a la compilación de desechos domésticos y clínicos estos permiten el crecimiento de especies patógenas y baterías oportunistas (Pagalilauan et al., 2018) que se transportan en el aire. La exposición a estos bioaerosoles se asocian a una amplia gama de enfermedades infecciosas, tóxicas, agudas, alergias y hasta cáncer (Douwes et al., 2003). Por la acumulación diaria de RSU y por su naturaleza, el Relleno Sanitario de Porlón de la ciudad de Riobamba resulta con un potencial alto de nivel de riesgo biológico para los trabajadores y habitantes del sector. 
Métodos: La toma de muestras de aire se realizó durante cuatro semanas de lunes a viernes distribuido en dos partes: la primera en el área de desechos hospitalarios y la segunda en el área de desechos comunes. El aire se aspiró con jeringuillas de $20 \mathrm{~cm}^{3}$ y se depositó en el caldo de cultivo Infusión Cerebro-Corazón, con 50 aspiraciones por cada una de las muestras. Estas muestras se incubaron a $37^{\circ} \mathrm{C}$ durante 48 horas para obtener un crecimiento óptimo de las bacterias para luego sembrar en dos medios de cultivo diferentes, siendo Tripteína Soya Agar y Agar MacConkey. Finalmente a las especies bacterianas identificadas se asoció a los grupos de riesgo mencionado por el Real Decreto 664/1997

Resultados: Se identificó 103 colonias morfológicamente diferentes de las cuales se observó 12 géneros diferentes de bacterias aisladas de los medios de cultivos: Shigella, Enterococcus, Enterobacter, Pantoea, Hafnia, Salmonella, Citrobacter, Staphylococcus, Escherichia, Klebsiella, Proteus y Providencia, de las 14 especies el $57 \%$ representan a nivel de riesgo biológico del grupo 2, el 29\% corresponden al grupo $3 y$ el $14 \%$ son especies no identificadas.

CONCLUSIÓN: Se determinaron concentraciones de unidades formadoras de colonias entre $1.95 \times 10^{+8} \mathrm{UFC} / \mathrm{ml}$ y $2.78 \times 10^{+9} \mathrm{UFC} / \mathrm{ml}$ con la presencia de bacterias peligrosas que pertenecen al nivel 2 y 3 en cuanto a riesgo biológico y que dieron mayor concentración a una temperatura de $16^{\circ} \mathrm{C}$, humedad relativa del $60 \%$, materia orgánica de $55 \%$ presente en el relleno.

Palabras Claves: Relleno sanitario, Bacterias patógenas, contaminación ambiental.

\section{Introducción.}

En el Ecuador como en otros países del mundo, la contaminación ambiental está asociada con la extracción y transformación de los recursos naturales; además de otros factores antropogénicos, como actividades industriales, comerciales, agropecuarias, tráfico vehicular y residuos sólidos. Los esfuerzos para controlar la contaminación del aire constituyen una preocupación ambiental de carácter mundial; organismos internacionales como la OMS, OPS, a partir de los años 1957 (OMS) y 1965 (OPS), vienen desarrollando programas de investigación, con el objeto de colaborar con los gobiernos miembros en el desarrollo de políticas adecuadas de control, a fin de reducir la contaminación del aire a través de técnicas de control y manejo general de la calidad del aire (Castro, 2009).

Los aerosoles biológicos corresponden a partículas de tamaño microscópico suspendidas en el aire, bien de origen natural o antropogénico que pueden afectar a los seres humanos, causándoles algún tipo de alergia, toxicidad o infección (Pereira et al., 2009) 
Los microorganismos se encuentran distribuidos en el suelo, aire, agua, plantas y animales, siendo uno de los grupos más abundantes en el ambiente.

Las aerobacterias son microorganismos suspendidos en el aire, introducidos por fuentes naturales y antropogénicas como: acción del viento y la lluvia, actividades agrícolas, vertido de residuos comunes, etc. La mayoría de las aerobacterias son patógenas para el ser humano, las cuales causan enfermedades o infecciones dependiendo de la vía de exposición, dichas bacterias pueden ser grampositivas o gramnegativas (González y Campo, 2016). Este trabajo tiene como objetivo determinar el nivel de riesgo biológico en el aire del relleno sanitario del Gobierno Autónomo Descentralizado Municipal de Riobamba (GADM Riobamba).

\section{Materiales y método.}

Esta investigación se desarrolló siguiendo el método aerobiológico propuesto por (Herrera et al., 2012) y la norma (INEN, 2015).

\section{Trabajo de campo.}

El relleno sanitario posee una extensión de 4 hectáreas que consta de dos zonas: desechos hospitalarios y desechos comunes. En las instalaciones del relleno sanitario se tomaron 40 muestras de aire, 2 muestreos por día durante 20 días, 10 días en la zona de desechos hospitalarios y 10 días en la zona de desechos comunes, mismos que se realizaron en puntos diferentes donde existe mayor probabilidad de contaminación biológica procedente de los desechos.

\section{Toma de muestras.}

Para el proceso de muestreo se utilizaron trajes adecuados para el muestreo.

Para la toma de muestras de aire se utilizaron jeringuillas de $20 \mathrm{~cm}^{3}$ estériles, sin aguja, por cada toma de muestra y zona de estudio, se realizaron 50 aspiraciones de aire. Estas aspiraciones se depositaron en matraces de vidrio que contenían caldo de cultivo Infusión Cerebro-Corazón (BHI-Brain Hearth Infusion).

Los matraces fueron sellados y solo abiertos para depositar las muestras evitando que la jeringuilla tope el caldo de cultivo. Cada 10 aspiraciones se agitó el matraz para que el medio tenga interacción con el aire.

Estos matraces se transportaron, almacenaron e incubaron a $37^{\circ} \mathrm{C}$ durante 48 horas permitiendo el crecimiento de microorganismos fácilmente observables por la presencia de turbidez del caldo de cultivo (Vargas, 2011).

\section{Trabajo de laboratorio.}




\section{Presencia de bacterias.}

Una vez transcurrido el tiempo de incubación, se realizó el aislamiento bacteriano en una cámara de flujo laminar vertical, para lo cual se prepararon diluciones en caldo peptona al 1\%; en Tripteína Soya Agar se hicieron diluciones $10^{4}, 10^{5}, 10^{6}$, y para Agar MacConkey se hicieron diluciones $10^{1}, 10^{2}, 10^{3}$. Mediante el uso de una micropipeta y puntas estériles se inoculó $100 \mu \mathrm{l}$ sobre Cajas Petri con medio sólido Tripteína Soya Agar y Agar MacConkey para cada día, zona y hora de muestreo, realizando difusión en placa con el asa Digralsky, y se incubaron a $37^{\circ} \mathrm{C}$ durante 48 horas.

Al finalizar el tiempo de incubación se evaluaron ambos medios de cultivo; para el Agar MacConkey la presencia de bacterias fermentadoras y no fermentadoras de lactosa, dichas bacterias con características macroscópicas diferentes fueron aisladas mediante estría simple con ayuda de una asa de punta redonda en cajas tri-petri, en el mismo medio de cultivo del que fueron extraídas, posteriormente se llevó a incubación durante 48 horas a $37^{\circ} \mathrm{C}$.

En el caso de Tripteína Soya Agar se evaluó el crecimiento de microorganismos aerobios, anaerobios facultativos y estrictos, para ello se utilizó cajas tri-petri con el mismo medio de cultivo del cual fueron extraídos dichos microorganismos. Se realizó el aislamiento mediante estría simple e incubó a $37^{\circ} \mathrm{C}$ por un período de 48 horas.

Al cabo de las 48 horas de incubación del aislamiento bacteriano, se procedió a la verificación de posibles contaminaciones, se realizó la purificación en caso de ser necesario y se almacenó para su posterior empleo en las pruebas IMViC (Vargas, 2011).

\section{Cantidad de microorganismos (Turbidez).}

El recuento de microorganismos viables se efectuó mediante el método turbidimétrico, con el que primeramente se elaboró una curva estándar denominada curva estándar de McFarland por medio de reacciones químicas que simulan el crecimiento bacteriano en un medio líquido. Para la elaboración de la curva estándar de McFarland se utilizó como estándares diferentes volúmenes de ácido sulfúrico al $1 \%$ y cloruro de bario al 1,175\% . (Ver Tabla 1)

Mediante el espectrofotómetro DR 5000 UV-Vis y tomando como blanco de medición el medio de cultivo BHI preparado y estéril, se midió la turbiedad de los 40 muestreos aerobiológicos realizados en el Relleno Sanitario del GADM de Riobamba y a una longitud de onda de 600nm., obteniendo el número de unidades formadoras de colonias por mililitro (UFC/ml).

\section{Cuantificación directa de UFC/ml.}




\section{Recuento en placa}

Transcurrido el tiempo de incubación de 48 horas de las muestras aerobiológicas se prepararon diluciones seriadas al décimo en caldo peptona al 1\%:

- dil.(-1) 0,1 ml muestra + 0,9 ml solución fisiológica.

- $\quad$ dil.(-2) 0,1 $\mathrm{ml}$ dil.(-1) + 0,9 $\mathrm{ml}$ solución fisiológica.

- dil.(-6) 0,1 $\mathrm{ml}$ dil.(-5) + 0,9 ml dilución fisiológica.

A continuación, se inoculó $0,1 \mathrm{ml}(100 \mu \mathrm{l})$ de las diluciones -1, -2, -3 sobre Cajas Petri con medio sólido Agar MacConkey y las diluciones -4, -5, -6 en Tripteína Soya Agar realizando difusión en placa con el asa Digralsky. Las placas fueron incubadas 48 horas a $37^{\circ} \mathrm{C}$. Se contaron las colonias obtenidas en cada Caja Petri y de aquellas que tenían entre 30 y 300 colonias se calcularon las unidades formadoras de colonias por mililitro (UFC/ml), según la fórmula:

$$
\mathrm{UFC} / \mathrm{ml}=\frac{\boldsymbol{N} * \boldsymbol{F D}}{\boldsymbol{V}}
$$

donde:

- UFC: unidades formadoras de colonias

- $\quad \mathbf{N}$ : número promedio de colonias obtenidas para una dilución dada

- V: volumen inoculado

- FD: factor de dilución

(Universidad de Buenos Aires, 2010).

\section{Pruebas IMViC.}

Los microorganismos aislados fueron sometidos a pruebas bioquímicas para determinar su capacidad enzimática y poder identificarlas bibliográficamente como patógenas o no patógenas. Se emplearon 4 pruebas bioquímicas entre las que se encuentran: Indol, Rojo de Metilo, Voges-Proskauer y Citrato de Simmons. Los resultados se representan como positivos (+) o negativos (-) (INEN, 2015).

\section{Prueba de Indol.}

Se inoculó cada una de las bacterias aisladas con un asa de punta redonda en tubos de ensayo que contenían 5 mililitros de caldo de peptona al $1 \%$, e incubó a $37^{\circ} \mathrm{C}$ durante 48 horas. Una vez finalizado el período de incubación se añadió 3 gotas del reactivo de Kovac's a cada tubo de ensayo, en la cual en caso de ser una reacción positiva se forma un anillo en la superficie del medio de color rojo oscuro (+) y en su defecto formación de color amarillo (-) (MacFaddin, 2003).

\section{Prueba Rojo de Metilo.}

Se colocó 5 mililitros de medio de cultivo líquido RM-VP (Rojo de Metilo y VogesProskauer) en tubos de ensayo, donde se inoculó cada una de las bacterias aisladas y 
posteriormente se incubó a $37^{\circ} \mathrm{C}$ durante 48 horas. Una vez finalizado el período de incubación se añadió 3 gotas de solución de rojo de metilo al 0,2\%, en la cual el caldo de cultivo se torna de color rojo si es un resultado positivo (+), caso contrario el caldo se torna de color amarillo si es un resultado negativo (-) (INEN, 2015).

\section{Prueba Voges-Proskauer.}

Se utilizaron tubos de ensayo con 5 mililitros de medio de cultivo líquido RM-VP, posteriormente se inoculó cada una de las bacterias aisladas e incubó a $37^{\circ} \mathrm{C}$ durante 48 horas. Finalizado el período de incubación se añadió 2 gotas de solución de hidróxido de potasio $(\mathrm{KOH})$ al $40 \%$ y 3 gotas de $\alpha$-naftol al $6 \%$, se agitaron y se dejó reposar durante 5 minutos. Esta prueba se evaluó mediante la formación de una capa en la superficie del medio de color rojizo, la cual se tomó como resultado positivo (+) (INEN, 2015).

\section{Prueba Citrato de Simmons.}

Para esta prueba se emplearon tubos microbiológicos de tapa rosca en los cuales se esterilizó medio de cultivo sólido Simmons Citrate y se dejó enfriar en posición inclinada. Con un asa de punta redonda se realizó estrías de todas las bacterias aisladas previamente y se incubaron durante 48 horas a $37^{\circ} \mathrm{C}$. En caso de ser un resultado positivo (+) se evidencia el color azul de bromotimol en el medio (INEN, 2015).

\section{Preservación de bacterias con glicerol.}

Las bacterias aisladas fueron transferidas a caldo TSA (Tripteína Soya Agar) que contenía $15 \%$ de glicerol y se almacenó a $-80^{\circ} \mathrm{C}$.

\section{Diseño Experimental.}

Según lo planificado en la metodología del proceso, se realizó un diseño experimental del tipo $\mathrm{AxBxC}$ en el cual se consideró tres factores; factor $\mathrm{A}$ : sectores de muestreo, factor $\mathrm{B}$ : horas de muestreo y factor $\mathrm{C}$ : días de muestreo. La toma de muestras se realizó durante cuatro semanas de lunes a viernes distribuido en dos partes: la primera parte para el área de desechos hospitalarios y la segunda parte para el área de desechos comunes.

\section{Resultados.}

\section{Crecimiento microbiano.}

\section{Crecimiento bacteriano.}

El crecimiento bacteriano se evidenció por el método de turbidez, el mismo que se identificó por el cambio de coloración de ámbar brillante transparente a un color opaco turbio. Además, la formación de nata en la superficie del medio de cultivo, corroboró la existencia de colonias bacterianas. Estos cambios en los medios de cultivo se produjeron luego del periodo de incubación, mencionado en la metodología. 


\section{Cantidad de microorganismos (Turbidez).}

El método de turbidez es un estudio cuantitativo de concentración microbiana, para el cual se requirió el empleo de la curva estándar de crecimiento microbiano, conocida como escala de McFarland, la cual brindó los parámetros necesarios por medio de reacciones químicas para conocer un valor estimado de microorganismos por métodos turbidimétricos y espectrofotométricos.

\section{Difusión en placa.}

\section{Difusión en placa para bacterias.}

La siembra realizada de las 40 muestras (tratamientos) correspondientes al periodo de muestreo, fue realizado por el método de difusión en placa en los medios de cultivo Agar MacConkey con diluciones $10^{1}, 10^{2}, 10^{3}$, donde el crecimiento fue minoritario y Tripteína Soya Agar con diluciones $10^{4}, 10^{5}, 10^{6}$, en el cual se evidenció un crecimiento favorable.

En el medio de cultivo Agar MacConkey se realizaron diluciones $10^{1}, 10^{2}, 10^{3}$, para el área de desechos hospitalarios y desechos comunes, determinándose que en el área de depósito de desechos comunes existió mayor concentración de microrganismos y en el área de depósito de desechos hospitalarios no presento crecimiento. En este medio no hubo crecimiento en muestras provenientes del área de desechos hospitalarios debido a que es un medio diferencial selectivo en el cual principalmente podemos encontrar Enterobacteriaceae y otros tipos de bacilos gramnegativos, que presumiblemente son los tipos de microorganismos que se aislaron del área de desechos comunes (Bowen et al., 2014).

En el medio de cultivo Tripteína Soya Agar se realizaron diluciones $10^{4}, 10^{5}, 10^{6}$, para el área de desechos hospitalarios y desechos comunes, se evidenció que en la mayoría de las muestras hubo crecimiento, esto debido a que el medio de cultivo no es selectivo, lo cual favorece al desarrollo de microorganismos aerobios, anaerobios facultativos y estrictos (Aravanlabs, 2017).

\section{Aislamiento microbiano.}

\section{Aislamiento bacteriano.}

Se aislaron 103 colonias macroscópicamente diferentes por medio de la técnica de estría simple, del total de estas colonias 94 fueron asiladas en medio de cultivo Tripteína Soya Agar y 9 en medio de cultivo Agar MacConkey.

Las colonias aisladas fueron codificadas adecuadamente con el fin de facilitar su identificación en el proceso de aislamiento. Cada colonia respectivamente codificada fue aislada en cajas tri-petri con el mismo medio de cultivo del que procedía, lo que permitió 
que las funciones metabólicas de los microorganismos no fueran afectadas por el cambio de nutrientes presentes en el medio.

Se identificó que en la totalidad de las cajas tri-petri con las colonias aisladas luego de las 48 horas de incubación hubo crecimiento bacteriano prolifero. Este crecimiento de colonias bacterianas fue apto para su empleo en las posteriores pruebas IMViC, detalladas en la metodología. Aquellas colonias que presentaron contaminación, fueron purificadas nuevamente hasta obtener el resultado deseado.

\section{Pruebas IMViC.}

Las pruebas IMViC se realizaron a 103 bacterias macroscópicamente diferentes aisladas de las muestras analizadas del aire de las zonas de desechos hospitalarios y desechos comunes del Relleno Sanitario del GADM de Riobamba.

Entre las pruebas realizadas estuvieron la prueba de Indol, Rojo de Metilo, Voges Proskauer y Citrato de Simmons. Dichas pruebas IMViC fueron de análisis cualitativo, utilizando un criterio de resultados positivos (+) o negativos (-).

Gráfico 1: Repetitividad del aislamiento microbiano durante la fase experimental del proyecto

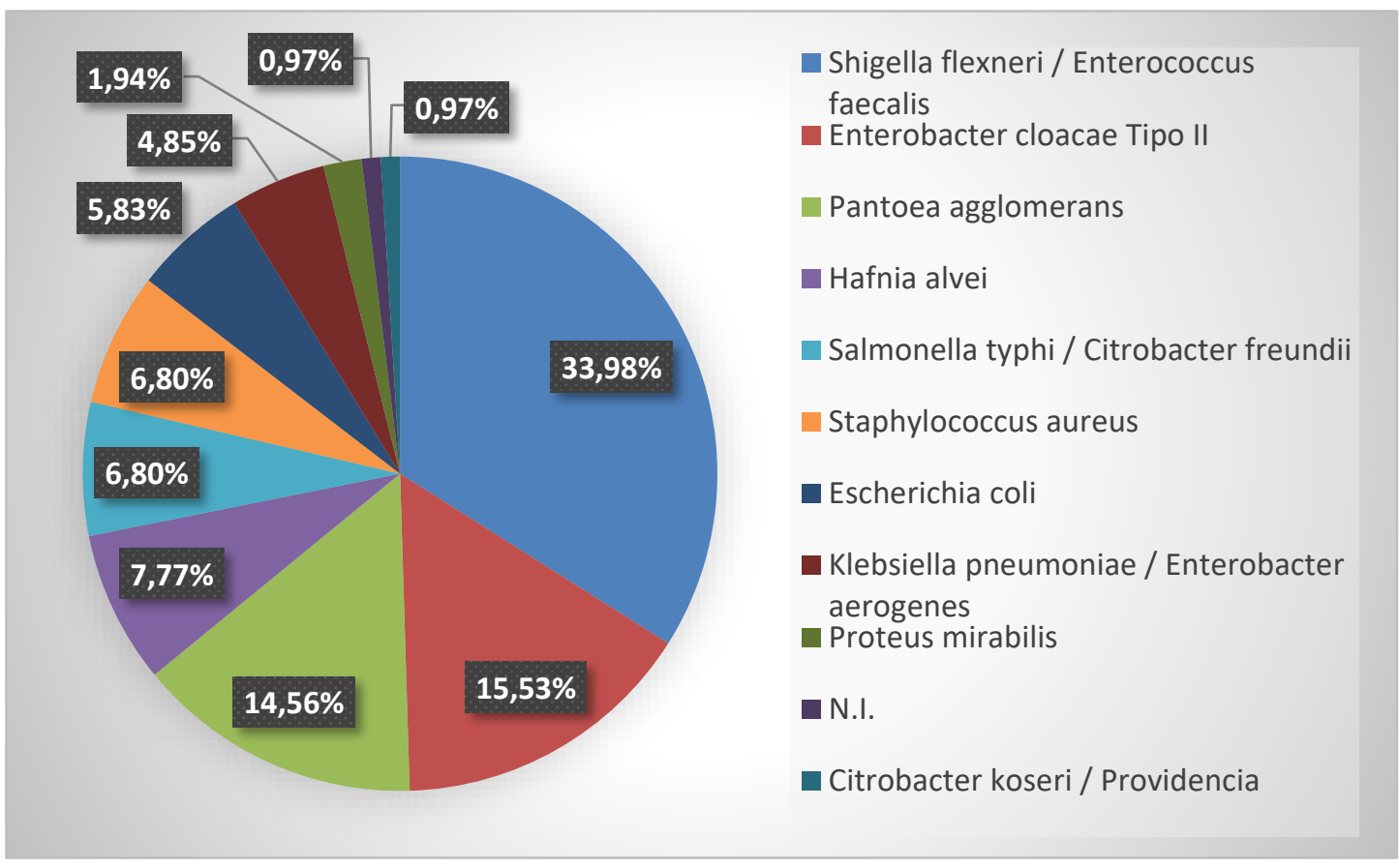

Elaborado por: Grupo de Investigación. 
En el Gráfico 1, se puede observar el porcentaje de repetitividad de cada especie de microorganismo, a partir de las 103 bacterias aisladas. Los microrganismos con mayor presencia fueron Shigella flexneri / Enterococcus faecalis con 35 repeticiones, lo que corresponde a un porcentaje de $33,98 \%$ del total de bacterias aisladas. Las especies de microorganismos con el segundo porcentaje más alto fueron Enterobacter cloacae Tipo II, con 15,53\% correspondiente a 16 repeticiones; seguido por Pantoea agglomerans con $14,56 \%$, equivalente a 15 repeticiones.

La especie de Hafnia alvei presentó una frecuencia de incidencia del 7,77\%, correspondiente a 8 repeticiones; las especies de Salmonella typhi / Citrobacter freundii y Staphylococcus aureus, con 7 repeticiones cada una, representaron el 6,80\% del total de bacterias aisladas respectivamente. La especie Escherichia coli presentó el 5,83\% el cual corresponde a 6 repeticiones; Klebsiella pneumoniae / Enterobacter aerogenes representó el 4,85\% con 5 repeticiones; Proteus mirabilis con 2 repeticiones correspondiente al 1,94\% de presencia bacteriana y finalmente Citrobacter koseri / Providencia con $0,97 \%$ y 1 repetición, siendo estas dos últimas especies los porcentajes más bajos de repetitividad. Además, también un $0,97 \%$ del total, correspondió a una bacteria que no se pudo identificar, a causa de que no se encontró resultados estandarizados.

\section{Cuantificación directa de UFC/ml.}

\section{Recuento en placa.}

El recuento en placa fue utilizado para determinar la concentración bacteriana de la muestra. El recuento de microorganismos, se basó en el conteo de colonias visibles, en un rango de 30 a 300 colonias. Sin embargo, la muestra no fue totalmente homogénea con respecto a su composición microbiológica, es decir, presentó muchos errores al definir la concentración microbiana. Posterior al conteo de colonias visibles, se consideró que la colonia estaba compuesta por unidades formadoras de colonia (UFC) y se determinó la concentración microbiana aplicando la ecuación expuesta en la metodología.

\section{Diseño experimental.}

El paquete estadístico Infostat estudiantil, fue la herramienta de análisis estadístico seleccionado para la investigación, con la finalidad de desarrollar la prueba de Tukey con un diseño experimental del tipo $\mathrm{AxBxC}$ a un nivel de confianza del $95 \%$ de los datos obtenidos de la medición por el método de turbidez. En total se obtuvo 40 muestras, un coeficiente de correlación del 77\% y un coeficiente de variación del 37,52\%, por lo tanto, los resultados obtenidos entre muestras y réplicas no presentaron variabilidad respecto a la zona de muestreo.

\section{Discusión.}

Los resultados muestran que la mayor variedad de microrganismos se presentó en el tratamiento a1b2c3, este tratamiento correspondió al área de desechos hospitalarios del día 
miércoles a las 15:00. Las bacterias que se identificaron bajo estas condiciones fueron: Enterobacter cloacae Tipo II, Shigella flexneri, Enterococcus faecalis, Klebsiella pneumoniae, Enterobacter aerogenes, Proteus mirabilis, Pantoea agglomerans, Salmonella typhi, Citrobacter freundii. Sin embargo, para el caso de desechos comunes el tratamiento que mayor variedad presentó fue el tratamiento a2b2c3 del día miércoles a las 15:00. En este tratamiento se evidenció el crecimiento de Shigella flexneri, Enterococcus faecalis, Klebsiella pneumoniae, Enterobacter aerogenes, Hafnia alvei, Enterobacter cloacae Tipo II. Esto se debe a que previo a la toma de muestras tanto los desechos hospitalarios como los desechos comunes fueron vertidos, lo que incremento la concentración de microorganismos del aire, lo cual causa un gran riesgo para el personal que se encuentra expuesto.

Con la finalidad de determinar el objetivo planteado del estudio, en el Gráfico 2 se observa los resultados de la interacción de los factores: factor A: zonas de muestreo, factor B: horas de muestreo y factor $\mathrm{C}$ : días de muestreo en relación al valor de las medias de concentración de unidades formadoras de colonias por mililitro (UFC/ml) del medio de cultivo BHI mostraron que el tratamiento a1b1c5, fue el tratamiento que mayor concentración y riesgo biológico presento. Dicho tratamiento correspondió al muestreo realizado en la zona de desechos hospitalarios, a las 10:00 am del día viernes. La concentración alta de microorganismo en el aire puede ser el causante de posibles enfermedades por exposición a los trabajadores del Relleno Sanitario del GADM de Riobamba.

Gráfico 2: Concentración de microorganismos (UFC/ml) obtenidos por el método turbidimétrico de la combinación de los factores $\mathrm{AxBxC}$.

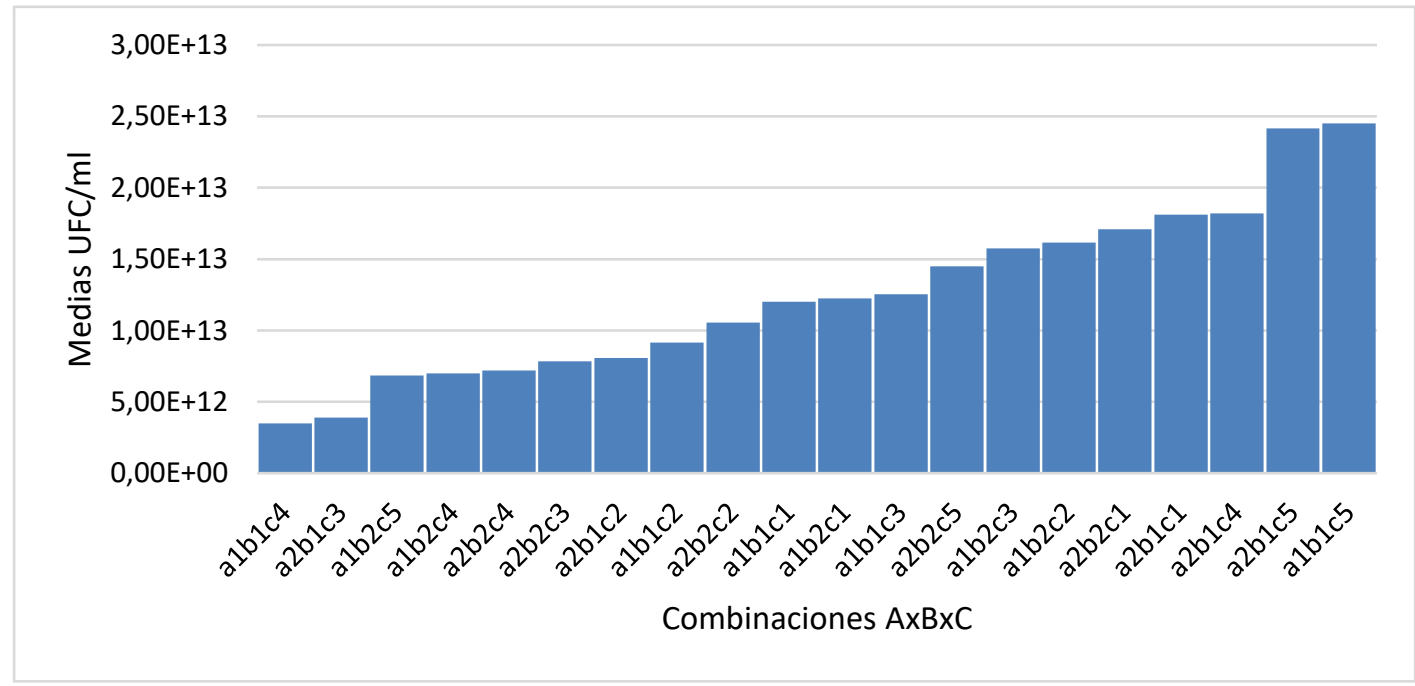

Elaborado por: Grupo de Investigación. 


\section{Conclusiones.}

- Por medio del estudio realizado se identificó que los microorganismos suspendidos en el aire del Relleno Sanitario del Gobierno Autónomo Descentralizado Municipal de Riobamba (GADM Riobamba) en su mayoría son bacterias gramnegativas pertenecientes a la familia Enterobacteriaceae (enterobacterias), identificando también bacterias grampositivas; de las cuales algunas son de alta peligrosidad con niveles de riesgo de 2 y 3 según el Real Decreto 664/1997; ocasionando enfermedades e infecciones al ser humano; estas bacterias se desarrollan adecuadamente a temperaturas entre 25 y $40{ }^{\circ} \mathrm{C}$ por lo que son microorganismos mesófilos.

- Se determinó la cantidad de unidades formadoras de colonia por mililitro de aire (UFC/ml) por medio de la turbidez con la utilización de una curva de calibración McFarland cuyo coeficiente de determinación fue 99,35\%, se encontraron concentraciones entre 1,95E+08 UFC/ml y 2,78E+09 UFC/ml, dichas concentraciones no pueden ser evaluadas bajo criterios debido a que no se ha establecido normativas en nuestro país, estas concentraciones se dieron bajo las siguientes condiciones temperatura de $16^{\circ} \mathrm{C}$, humedad relativa del $60 \%$, materia orgánica de $55 \%$ presente en el relleno.

- Se comparó dos métodos cuantitativos de determinación del crecimiento microbiano, un método indirecto de turbidimetría que utiliza la curva estándar de McFarland por medio de las absorbancias para estimar la cantidad de UFC/ml presentes en el medio, el cual muestra la presencia de microorganismos vivos y muertos sin poder distinguirlos; y un método directo de recuento en placa que muestra la presencia de microorganismos vivos permitiendo estimar las UFC/ml a través de una ecuación.

- Para el crecimiento de los microorganismos se utilizó dos medios de cultivo: Agar MacConkey que permite el crecimiento de bacterias gramnegativas e inhibe bacterias grampositivas debido a las sales biliares contenidas en el medio; y Tripteína Soya Agar (TSA) que es un medio no diferencial el cual por sus nutrientes es utilizado para el crecimiento de todo tipo de microorganismos.

- Se identificó la presencia de 103 bacterias patógenas, y por medio de las pruebas IMViC se determinaron que fueron grampositivas y gramnegativas; Shigella flexneri fue la bacteria que se aisló con mayor frecuencia en los medios de cultivo catalogada de alta peligrosidad por el Real Decreto 664/1997 con un nivel de riesgo de tipo 2, provocando enfermedades en los trabajadores o personas expuestas a esta, con la posibilidad de tratamiento; la bacteria Shigella flexneri soporta temperaturas de 7 a $45^{\circ} \mathrm{C}$, por lo que es peligrosa para la salud humana ya que su crecimiento óptimo se a la temperatura corporal. 


\section{Referencias bibliográficas.}

Aravanlabs. (2017). Placas de Petri Triptona Soja Agar. from http://aravanlabs.com.uy/wpcontent/uploads/2015/12/especificaciones-placas-de-petri-triptona-soja-agar.pdf

Bowen, C., Mardones, M. y Velasquez, L. (2014). Guia de laboratorio de microbiología. Retrieved enero 15, 2018, from ftp://ftp.puce.edu.ec/Facultades/Medicina/CEAACES/PLAN\%20CURRICULAR/C 3.2\%20PRACTICAS\%20Y\%20CORRESPONDENCIA\%20CURRICULAR/GU\% C3\%8DAS\%20DE\%20PRACTICA\%20DE\%20LAB/GUIA\%20DE\%20LABORA TORIO\%20DE\%20MICROBIOLOG\%C3\%8DA.pdf

Castro, C. (2009). Evaluación aeromicológica en la calidad del aire de la zona aledaña al relleno sanitario Portillo Grande en el otoño del 2009. (Tesis de postgrado), Universidad Nacional Agraria La Molina, Lima, Perú. Retrieved from http://www.lamolina.edu.pe/postgrado/cienciambientales/Tesis_Maestr\%C3\%ADa_ Clara.\%20Summary.\%20pdf.pdf

Douwes, J., Thorne, P., Pearce, N. y Heederik, D. (2003). Bioaerosol health effects and exposure assessment: Progress and prospects. Annals of Occupational Hygiene, 47(3), 187-200. doi: 10.1093/annhyg/meg032

González, E. y Campo, M. (2016). Evaluación de bioaerosoles desde un relleno sanitario en el departamento del Atlántico. (Tesis de pregrado), Universidad de la Costa, Barranquilla, Colombia. Retrieved from http://repositorio.cuc.edu.co/xmlui/bitstream/handle/11323/945/1140864876\%20$\% 201140870541 \% 20 \% 20$.pdf? sequence $=1 \&$ is Allowed $=\mathrm{y}$

Herrera, K., Cóbar, O., De León, J., Rodas, A., Boburg, S., Quan, J., Pernilla, L., Mancilla, C. y Gudiel, H. (2012). Impacto de la calidad microbiológica del aire externo en el ambiente interno de cuatro laboratorios de instituciones públicas en la ciudad de Guatemala y Bárcenas, Villa Nueva. Revista Científica - IIQB - Instituto de Investigaciones Químicas y Biológicas - Facultad de Ciencias Químicas y Farmacia, 22(1), 30-38.

INEN. (2015). Control microbiológico de los alimentos. Detección y recuento de Escherichia coli presuntiva por la técnica del número más probable. Quito-Ecuador: Instituto Ecuatoriano de Normalización Retrieved from http://www.normalizacion.gob.ec/wpcontent/uploads/downloads/2015/07/nte_inen_1529-8.pdf.

Jimenez, A. (2012). Propuesta para el manejo de lixiviados generados en el relleno sanitario del cantón salcedo, provincia de Cotopaxi. (Ingeniero en Medio Ambiente), Universidad Técnica de Cotopaxi. Retrieved from http://repositorio.utc.edu.ec/handle/27000/582

MacFaddin, J. F. (2003). Pruebas bioquímicas para la identificación de bacterias de importancia clínica (3 ed.). Buenos Aires, Argentina: Editorial Médica Panamericana. 
Pagalilauan, H. A. M., Paraoan, C. E. M. y Vital, P. G. (2018). Detection of pathogenic bioaerosols and occupational risk in a Philippine landfill site. Archives of Environmental and Occupational Health, 73(2), 107-114. doi: 10.1080/19338244.2017.1299087

Pereira, A. M. V., Jiménez, M. R. M., De La Cruz, Y. P. S. y Caicedo, Y. C. (2009). Emisiones Atmosféricas de Origen Biológico: Generalidades, impactos asociados y medidas de control de aerosoles Fungi. Revista Retakvn, 2(1), 2027-2162.

Universidad de Buenos Aires. (2010). Microbiología e Inmunología: Departamento de Química Biológica.

Vargas, K. (2011). Indicadores microbiológicos de calidad ambiental del botadero La Muyuna. Universidad Nacional Agraria de la Selva Tingo María, Perú. Retrieved from

http://s3.amazonaws.com/academia.edu.documents/32857008/INDICADORES_MI CROBIOLOGICOS_DE_CALIDAD_AMBIENTAL_DEL_BOTADERO_LA_MO YUNA.pdf?AWSAccessKeyId=AKIAIWOWYYGZ2Y53UL3A\&Expires $=149913$ 4409\&Signature=nOkpQyOCMebPFsltxoR1\%2B7h9GQI\%3D\&response-contentdisposition=inline \%3B\%20filename\%3DINDICADORES_MICROBIOLOGICOS_ DE_CALIDAD_A.pdf 


\section{Para citar el artículo indexado.}

Córdova M., Vega J., Ruíz O., Campaña B. \& Navarrete G. (2018). Contaminación Por Bioaerosoles En El Relleno Sanitario Del Gobierno Autonomo Descentralizado Municipal De Riobamba. Revista electrónica Ciencia Digital 2(3), 443-457. Recuperado desde: http://cienciadigital.org/revistacienciadigital2/index.php/CienciaDigital/article/view/168/14 $\underline{8}$

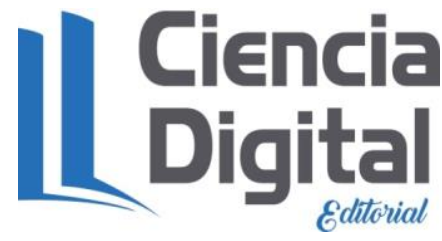

El artículo que se publica es de exclusiva responsabilidad de los autores y no necesariamente reflejan el pensamiento de la Revista Ciencia Digital.

El articulo queda en propiedad de la revista y, por tanto, su publicación parcial y/o total en otro medio tiene que ser autorizado por el director de la Revista Ciencia Digital.
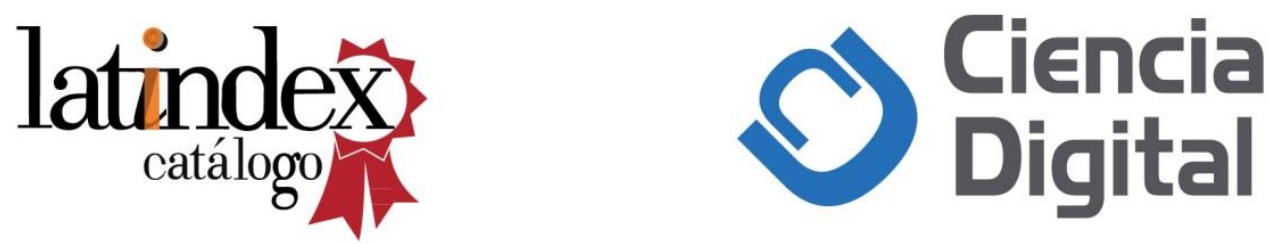